\title{
The importance of empathy in health and nursing care
}

\author{
A importância da empatia no cuidado em saúde e enfermagem \\ La importancia de la empatía en el cuidado de la salud y en la enfermería
}

\begin{abstract}
Raquel Terezam', Jessica Reis-Queiroz', Luiza Akiko Komura Hoga"
' Universidade de São Paulo, School of Nursing, Postgraduate Program in Nursing. São Paulo, Brazil. "Universidade de São Paulo, School of Nursing, Department of Maternal and Child Nursing and Psychiatry. São Paulo, Brazil.

How to cite this article:

Terezam R, Reis-Queiroz J, Hoga LAK. A importância da empatia no cuidado em saúde e enfermagem. Rev Bras Enferm [Internet]. 2017;70(3):669-70. DOI: http://dx.doi.org/10.1590/0034-7167-2016-0032
\end{abstract}

Submission: 01-29-2016

"In her book "Cultivating Empathy"(1), Kathleen Stephany, psychologist and professor at the College of Health Sciences at Douglas College, writes about empathy, which she considers to be the basis of effective communication and one of the most important skills to be developed by human beings. Empathy is the ability to put oneself in the place of other people in order that a person can visualize and feel the experiences of other(s) from the same perspective. It is a fundamental attitude for the physical and mental well-being of both people. An example of this mutual benefit is in the study developed by Baron-Cohen ${ }^{(2)}$. By means of magnetic resonance, she verified the illumination of neural circuits at the times people expressed empathic acts.

The first chapter highlights the importance of parents practicing empathy towards their children. This parental attitude helps to promote the self-esteem of their children, who will become healthy adults with the ability to be empathetic towards other people just as their parents did with them. Likewise, health professionals should be aware of their own feelings to be in a better position to understand better the emotions and feelings experienced by patients and, consequently, establish empathic relationships with them.

In the second chapter are described experiences of people who have suffered as a consequence of health professionals' lack of empathy. According to patients' evaluation, even if the nursing team members have adequate technical knowledge, the lack of empathy in the care process decreases the levels of satisfaction with the care received. Environmental factors are emphasized as causing losses in empathy, since the neural circuits responsible for this ability can suffer progressive
Approval: 09-19-2016

deterioration resulting from chronic stress, alcohol abuse, depression or hormonal imbalance, among others.

The self-knowledge and ability to discern between one's own emotions and those of others, and to be attentive to the effects of one's own words and the reactions in others also represent important aspects to adopt empathic attitudes. The absence of prior judgment, receptive and attentive listening, care for non-verbal communication, consideration of other people's perceptions of our traits, and the learning generated by one's own experiences also contribute to develop the ability of empathy. A calm and clear mind, peaceful sleep and a cheerful countenance are conditions that benefit the establishment of the empathic attitude.

The author alerts about the need to learn to deal with angry people and/or those who are going through difficult times, such as illness or death. In these circumstances, judgmental behaviors should be avoided by understanding that emotional stress generates the regressive state, which reflects on everyday behavior. Terminal diseases and mourning are part of the human experience and therefore, should not be seen as failures.

In the last chapter of her book, Stephany presents the concept of 'compassion fatigue', related to the gradual loss of empathy that can affect health professionals. In the beginning of their careers, these professionals demonstrate a high level of empathy. However, it can be reduced by daily stress caused by continuous exposure to patient suffering. Disregarding other people, emotional exhaustion, anger and sleep disorders are the most obvious symptoms of fatigue from the feeling of compassion. When observing one or a few of these symptoms, it

\section{CORRESPONDING AUTHOR Raquel Terezam E-mail: raquel.terezam@usp.br}


is prudent that practitioners seek professional help, and also try to recognize themselves as vulnerable people and forgive themselves.

The reading of this book encourages health professionals, especially nursing professionals, to reflect on the nursing practice in today's world, full of difficulties. It shows the need for health professionals being empathic with themselves in order to offer effective care filled with an empathic attitude. The search for empathic care must be constant, and the book author presents the necessary tools to put this ideal into practice. The set of data reported in this review serves as an incentive for the complete reading of Stephany's work. The professional who reads this book will surely have a qualitative leap for more empathic health care and in the daily contact with people.

\section{ACKNOWLEDGEMENTS}

We thank Kathleen Stephany for authorizing this review.

\section{REFERENCES}

1. Stephany K. Cultivating empathy: inspiring health professionals to communicate more effectively. Sharjah: Bentham Science Publishers; 2014. 194 p.

2. Baron-Cohen S. The science of evil: on empathy and the origins of cruelty. New York: Basic Books; 2011. 272 p. 